\title{
Metabolic and Neurologic Consequences of Chronic Lopinavir/ Ritonavir Administration to C57BL/6 mice
}

\author{
Paul J. Pistell ${ }^{1}$, Sunita Gupta ${ }^{1}$, Alecia G. Knight ${ }^{1}$, Michelle Domingue ${ }^{1}$, Romina M. \\ Uranga $^{2}$, Donald K. Ingram ${ }^{1}$, Indu Kheterpal ${ }^{1}$, Carmen Ruiz ${ }^{1}$, Jeffrey N. Keller ${ }^{1}$, and \\ Annadora J. Bruce-Keller ${ }^{1,}$, \\ ${ }_{1}^{1}$ Pennington Biomedical Research Center, Louisiana State University System, Baton Rouge, LA \\ 70808 \\ 2 Instituto de Investigaciones Bioquímicas de Bahía Blanca, Universidad Nacional del Sur and \\ Consejo Nacional de Investigaciones Científicas y Técnicas, Bahía Blanca, Argentina
}

\begin{abstract}
It is well established that HIV antiretroviral drugs, particularly protease inhibitors, frequently elicit a metabolic syndrome that may include hyperlipidemia, lipodystrophy, and insulin resistance. Metabolic dysfunction in non-HIV-infected subjects has been repeatedly associated with cognitive impairment in epidemiological and experimental studies, but it is not yet understood if antiretroviral therapy-induced metabolic syndrome might contribute to HIV-associated neurologic decline. To determine if protease inhibitor-induced metabolic dysfunction in mice is accompanied by adverse neurologic effects, C57BL/6 mice were given combined lopinavir/ritonavir (50/12.5 to $200 / 50 \mathrm{mg} / \mathrm{kg}$ ) daily for 3 weeks. Data show that lopinavir/ritonavir administration caused significant metabolic derangement, including alterations in body weight and fat mass, as well as dose-dependent patterns of hyperlipidemia, hypoadiponectinemia, hypoleptinemia, and hyperinsulinemia. Evaluation of neurologic function revealed that even the lowest dose of lopinavir/ritonavir caused significant cognitive impairment assessed in multi-unit T-maze, but did not affect motoric functions assessed as rotarod performance. Collectively, our results indicate that repeated lopinavir/ritonavir administration produces cognitive as well as metabolic impairments, and suggest that the development of selective aspects of metabolic syndrome in HIV patients could contribute to HIV-associated neurocognitive disorders.
\end{abstract}

\section{Keywords \\ HIV-associated neurocognitive disorders; HIV protease inhibitors; hypertriglyceridemia; metabolic syndrome}

\section{INTRODUCTION}

In the US and other developed nations, survival rates associated with HIV infection have improved dramatically since the introduction of combination antiretroviral therapies (ART),

\footnotetext{
*Correspondence: Annadora J. Bruce-Keller, Inflammation and Neurodegeneration Laboratory, Pennington Biomedical Research Center/LSU, 6400 Perkins Road, Baton Rouge, LA 70808, Phone (225)763-2735 FAX (225)763-0260 annadora.brucekeller@pbrc.edu.

Publisher's Disclaimer: This is a PDF file of an unedited manuscript that has been accepted for publication. As a service to our customers we are providing this early version of the manuscript. The manuscript will undergo copyediting, typesetting, and review of the resulting proof before it is published in its final citable form. Please note that during the production process errors may be discovered which could affect the content, and all legal disclaimers that apply to the journal pertain.
} 
which act to restrict viral replication, and accordingly raise CD4 cell counts, prevent opportunistic infections, and improve and extend health-related quality of life (reviewed by Quinn, 2008). Indeed, the advent of ART has revolutionized the care of HIV-positive patients, triggering an evolution from palliative, end-of-life care to long-term clinical management of chronic infection. ART elements can currently be divided into five major drug classes: protease inhibitors (PIs; including ritonavir, lopinavir, and tipranavir), nucleoside reverse transcriptase inhibitors (NRTIs), non-nucleoside reverse transcriptase inhibitors (NNRTIs), and the emerging entry and integrase inhibitors.

Despite the unquestionable life-saving effects of ART, epidemiological data have revealed significant iatrogenic metabolic complications of these drugs. These metabolic disturbances produce clinical syndromes that can include dyslipidemia, insulin resistance, and lipodystrophy (reviewed by Herman and Easterbrook, 2001; Anuurad et al., 2009), which not only affect patient health, but also limit ART compliance (reviewed by Schambelan et al., 2002). Although multiple factors influence metabolism in HIV patients, exposure to PIs is thought to play a major and specific role in the development of dyslipidemia, as PIs are well-known to profoundly affect serum and hepatic triglycerides, body fat composition, and adipokine levels both in humans and mice (Lenhard et al., 2000a,b,c; Tsiodras et al., 2000; Prot et al., 2006; Moyle, 2007; Thomas and Smart, 2007; Jiang et al., 2009).

While the widespread availability of ART has lead to remarkable improvements in immune health outcomes, HIV-associated neurologic disorders remain a significant public health concern. HIV-associated neurocognitive disorders (HAND), AIDS dementia complex, HIV-1 associated cognitive-motor complex, and (collectively termed neuroAIDS) are all neurological syndromes that can occur in conjunction with HIV infection (reviewed in Ances and Ellis, 2007; Nath et al., 2008; Power et al, 2009). While the incidence of the most severe forms of neuroAIDS (e.g., AIDS dementia complex) have significantly declined in the era of ART (Sacktor et al., 2001), the incidence and prevalence of milder forms of neuroAIDS (e.g., HAND) have been relatively stable (McArthur, 2004) and may have even increased with widespread ART utilization (McArthur et al., 2003). While some ART drugs, including the non-nucleoside analog efavirenz, are more strongly associated with adverse neurologic side effects (Cespedes and Aberg, 2006) and could perhaps have direct CNS effects, most studies suggest that better neurologic outcomes can be achieved by ART elements with higher degrees of CNS penetration (De Luca et al., 2002; Patel et al., 2006). Thus, the profile of neuroAIDS in the United States has changed significantly in response to the widespread availability of ART, and new physiologic issues (potentially including metabolic disturbances) likely participate in the sequelae of HAND in the ART era. Indeed, emerging epidemiological and experimental studies clearly demonstrate that metabolic dysfunction increases brain pathogenesis and decreases cognitive function (reviewed by Bruce-Keller et al., 2009). Furthermore, recent reports indicate that HIV patients with metabolic compromise may have a significantly greater risk of developing neurologic complications, including both cognitive and motor disturbances (Valcour et al., 2004, 2005, 2006, 2008; Bandaru et al., 2007). While the adverse metabolic effects of ART on atherosclerosis and cardiovascular risk are well known, effects of ART on neurologic function have not been directly examined. Thus, these studies were undertaken to determine the ability of ART-induced metabolic dysfunction to disrupt brain function in experimental animals. To this end, C57BL/6 mice were given lopinavir/ritonavir daily for 3 weeks, and then tested for both metabolic and neurologic function. 


\section{MATERIALS AND METHODS}

\subsection{Animal Treatments}

The Institutional Animal Care and Use Committee at the Pennington Center approved all experimental protocols, which were compliant with NIH guidelines on the use of experimental animals. 12 month-old male C57B1/6NIA mice were purchased from the National Institute on Aging contract facility maintained by Charles River Laboratories (Wilmimgton, MA). All mice were housed in standard cages with 12:12 light: dark cycle, and had ad libitum access to food and water throughout the study. Lopinavir/ritonavir (oral Kaletra, Abbott Laboratories), was diluted in a vehicle of $10 \%$ ethanol/15\% propylene glycol, and mice received daily intraperitoneal injections of vehicle or lopinavir/ritonavir at $50 / 12.5,100 / 25$, and $200 / 50 \mathrm{mg} / \mathrm{kg}$. This dose range was based on dosing guidelines for daily oral lopinavir/ritonavir in adult HIV patients $(800 / 200$ total $\mathrm{mg}$ or $10 / 2.5 \mathrm{mg} / \mathrm{kg}$ ), and on body surface area (BSA) normalization factors (Pinkel, 1958; Sawyer and Ratain, 2001; Reagan-Shaw et al., 2007), which translates $10 \mathrm{mg} / \mathrm{kg}$ in humans to approximately $125 \mathrm{mg}$ / $\mathrm{kg}$ in mice.

Body weight, body composition, food intake, and blood glucose of all mice were measured regularly throughout the duration of exposure. Food intake was calculated by regularly weighing the amount of food given to mice and calculating the daily loss. Body composition was measured using a Bruker minispec LF90 time domain NMR analyzer (Bruker Optics, Billerica MA). Glucose was measured in blood collected by tail nick using a glucometer (Ascensia Elite, Bayer, Mishawaka, IN).

All blood samples were taken after a brief ( $6 \mathrm{hr})$ fast. After behavioral testing, all mice were humanely euthanatized, and trunk blood, brain, and adipose tissue were collected. Data were compiled from 2 separate cohorts of mice, with a total of 9-20 animals in each group.

\subsection{UPLC-MRM-MS measures of lopinavir concentrations in serum and brain}

Liponavir concentrations in serum and brain tissue were quantified using reverse phase ultra performance liquid chromatography-multiple reaction monitoring -mass spectrometry (UPLC-MRM-MS). Serum and brain homogenates $(12 \mathrm{mg} / \mathrm{ml})$ were defrosted at $4^{\circ} \mathrm{C}$, deproteinized by adding chilled methanol (4x volume) and incubated at $-20^{\circ} \mathrm{C}$ for $1 \mathrm{~h}$. Samples were centrifuged $\left(20,800 \mathrm{~g}, 15 \mathrm{~min}, 4^{\circ} \mathrm{C}\right)$ and supernatants were evaporated to dryness. Samples were resuspended in a solvent containing $80 \%$ water, $20 \%$ acetonitrile and $0.1 \%$ formic acid. Reverse phase UPLC separations were conducted using a flow rate of 0.6 $\mathrm{mL} / \mathrm{min}$ with $0.1 \%$ formic acid as mobile phase $\mathrm{A}$ and $100 \%$ acetonitrile in $0.1 \%$ formic acid as mobile phase B. Samples were injected on a BEH C18 column $(1.7 \mu \mathrm{m}, 2.1 \times 50$ $\mathrm{mm}$, Waters Corp.) and eluted with a linear gradient of 20-97\% mobile phase B in 5 min. All samples were analyzed in triplicate. Samples eluted from the chromatographic column were ionized by the electrospray ionization (ESI) source and analyzed by the triple quadrupole mass spectrometer (XEVO TQMS, Waters Corp.) The mass spectrometer was operated in positive ion mode, with an electrospray voltage of $4 \mathrm{kV}$, cone voltage of $22 \mathrm{~V}$, extraction cone voltage of $3 \mathrm{~V}$, source temperature $150^{\circ} \mathrm{C}$ and desolvation temperature of $600{ }^{\circ} \mathrm{C}$. The mass/charge range was monitored for four MRM transitions (precursor to fragment ion transitions) 629.5/155.1, 629.5/120.1, 629.5/183.1 and 629.5/447.3 and the cycle (dwell time of $25 \mathrm{~ms}$ for each MRM transition) was repeated for the entire chromatographic gradient. The optimal collision energy for the four transitions listed above was 50,38, 22 and 14, respectively. Calibration standards were generated by spiking mouse blood serum and brain homogenates with lopinavir. Standard calibration curves were generated using $1 / \mathrm{X}$-weighted linear regressions and used to determine lopinavir concentration in samples. TargetLynx (Waters Corp.) was used for data processing. 


\subsection{Behavioral analysis of cognitive performance: Stone T-maze}

Cognitive ability was tested behaviorally on all mice using the five-segmented, Stone Tmaze as described in previously published reports (Pistell et al., 2009; Pistell and Ingram, 2010). Briefly, performance in this maze requires the mouse to learn the correct sequence of 13 consecutive left and right turns to reach the goal box and successfully escape the maze. Mice are motivated to escape because they are required to wade (not swim) through the maze, as the apparatus is maintained in a tray of water $\left(21-23^{\circ} \mathrm{C}\right)$ filled to a level $(1.5 \mathrm{~cm})$ that allows the mice to keep their head out of the water while maintaining contact with the floor, but the height of the maze prevents rearing. The day before acquisition testing, all animals were pre-trained to escape the water using a straight runway constructed of acrylic with opaque sides. For acquisition testing, mice were given 15 sequential trials in the Tmaze in a single day. Mice were tested in groups of 8-10 mice, and were run through such that the first trial was completed by all mice before proceeding to the second trial, insuring that each mouse had sufficient rest between trials to prevent any potential effects of fatigue. Trials were recorded using video tracking software (Viewpoint Lifesciences, Inc), and the latency to reach the goal box, and the numbers of errors committed were recorded and used as the primary measure of learning because it is unbiased by potential confounds resulting from differences in motor function. For the purpose of data analysis and presentation, maze acquisition data was collapsed into 5 separate blocks of 3 trials each.

\subsection{Behavioral analysis of motor performance: Rotarod}

Motor function was analyzed using a Five Station Rota-Rod Treadmill for Mouse (MedAssociates, St. Albans, VT). Each mouse was given three trials during which the starting speed of the rotarod was $4 \mathrm{rpm}$, but the rod accelerated to $40 \mathrm{rpm}$ over a period of five min. The amount of time the animal was able to remain on an accelerating rotating cylinder was recorded and used as the primary measure of motor function. The maximum trial length was $5 \mathrm{~min}$ and there was a 30 min rest period between each trial.

\subsection{Clinical Chemistry}

Trunk blood was allowed to clot at $4^{\circ} \mathrm{C}$ overnight and then centrifuged at $3000 \times \mathrm{g}$ for 30 minutes, and serum collected and either analyzed immediately or stored at $-80^{\circ} \mathrm{C}$. Levels of total cholesterol, triglycerides, and nonesterified fatty acids (NEFA) in sera were measured colorimetrically using commercially available kits (Wako Chemicals, Richmond, VA). Adiponectin, leptin, and insulin levels in serum were all evaluated by ELISA in accordance with the Manufacturer's assay protocol (R\&D Systems, Minneapolis, MN for adiponectin and leptin; and Crystal Chem Inc., Downers Grove IL for insulin) and read on a Victor plate reader (Perkin Elmer, Waltham, MA) set at 450nm with wavelength correction at 540nm.

\subsection{Statistical analyses}

All data are shown as mean \pm standard error of measurement. Body weight, body composition, food intake, and blood glucose levels were analyzed with 2-way, repeated measures analyses of variance (ANOVA) to determine main effects of treatment group and duration, followed by Bonferroni post-hoc comparisons to determine differences between lopinavir/ritonavir and vehicle groups. Stone maze performance was also analyzed with 2way repeated measures ANOVA to determine main effects of trail block and treatment, again followed by Bonferroni post-hoc comparisons to determine differences between lopinavir/ritonavir and vehicle groups. Rotarod, glucose, serum lipid, and serum hormone data were analyzed by 1-way ANOVA to determine group differences, followed by Tukey's post-hoc analyses to determine specific differences between lopinavir/ritonavir and vehicle groups. Statistical significance for all analyses was accepted at $\mathrm{p}<0.05$, and $*, * *$, and $* * *$ represent $\mathrm{p}<0.05, \mathrm{p}<0.01$, and $\mathrm{p}<0.001$, respectively. 


\section{RESULTS}

\subsection{Effects of lopinavir/ritonavir on body weight and composition}

The PI class of antiretroviral drug is most frequently associated with severe metabolic abnormalities both in humans and in mice (Lenhard 2000a,b,c; Tsiodras et al., 2000; Hurwitz et al., 2004; Prot et al., 2006; Moyle, 2007), and thus these studies were designed to evaluate the ability of PIs to disrupt neurologic as well as metabolic function. Combined lopinavir/ritonavir (Kaletra, Abbott Laboratories, Abbott Park, IL) is a cocktail prepared at a 4:1 ratio, and this specific drug was selected as it is both very commonly used in clinical settings to manage HIV (reviewed in Cvetkovic and Goa, 2003), and also has a strong association with metabolic derangement both in humans and in mice (Prot et al., 2006; Chandwani and Shuter, 2008). Dosing guidelines for oral lopinavir/ritonavir in adult HIV patients prescribe $10 \mathrm{mls}$ (or $800 / 200 \mathrm{mg}$ ) per day, which is approximately $10 / 2.5 \mathrm{mg} / \mathrm{kg}$ for an average $80 \mathrm{~kg}(175 \mathrm{lb})$ male. The calculation to accurately translate human to animal doses requires correction for body surface area (BSA) normalization (Reagan-Shaw et al., 2007), and dose translation calculations equate $10 \mathrm{mg} / \mathrm{kg}$ in humans to approximately 125 $\mathrm{mg} / \mathrm{kg}$ in mice (data not shown). To confirm the accuracy of BSA calculations, concentrations of lopinavir were measured in the serum of mice exactly 4 hours after intraperitoneal injection of either $100 \mathrm{gm}$ lopinavir $/ 25 \mathrm{mg}$ ritonavir $/ \mathrm{kg}$ or $50 / 12.5 \mathrm{mg} / \mathrm{kg}$, using UPLC-MRM-MS as described in Methods (Table 1). These data show that serum levels of lopinavir in this study approximate clinical levels, as Kaletra is reported by the drug Manufacturer (Abbott) to have a $\mathrm{C}_{\max }$ for lopinavir of $9.8+3.7 \mathrm{ug} / \mathrm{ml}$ approximately 4 hours after administration to adult HIV-positive patients. Additionally, UPLC-MRM-MS techniques were also used to measure lopinavir in the brains of mice treated acutely and euthanized exactly 4 hours after injection, and show that levels of lopinavir in brain were nearly 200 -fold lower than levels in serum (Table 1). Finally, brain levels of lopinavir were measured 24 hours after injection in mice treated daily with lopinavir/ritonavir for 21 days. These data show that brain lopinavir levels fall precipitously (by 10-20 fold) 24 hours after injection, and accordingly do not indicate that lopinavir accumulates in the brain following repeated daily administration.

Twelve-month old C57BL/6 mice were then administered a 21-day regimen of daily intraperitoneal injections of either vehicle (10\% ethanol/15\% propylene glycol) or low, medium, or high doses of lopinavir/ritonavir $(50 / 12.5,100 / 25$, or $200 / 50 \mathrm{mg} / \mathrm{kg}$ body weight). Overall body weight was recorded regularly as an index of overall health of the mice and to ensure that the mice were not made severely ill (cachexic) by the drugs, and indeed high doses $(200 / 50 \mathrm{mg} / \mathrm{kg}$ ) of PI produced severe weight loss (> 20\% of body weight, data not shown), and thus these higher doses were discontinued and not studied further. Statistical evaluation of the effects of low and medium doses of PI on body weight by repeated measures ANOVA revealed a significant main effect of treatment duration on body weight $\left(\mathrm{F}_{(2,44)}=58.81, \mathrm{p}<0.0001\right)$, but there was no significant effect of drug administration on body weight $\left(\mathrm{F}_{(2,44)}=1.512, \mathrm{p}=0.2317\right)$. However, there was a statistically significant interaction of treatment and drug $\left(\mathrm{F}_{(2,44)}=14.68, \mathrm{p}<0.0001\right)$, and post-hoc tests revealed that only the $100 / 25 \mathrm{mg} / \mathrm{kg}$ lopinavir/ritonavir caused significant weight loss, and only when measured at the end of exposure (Fig. 1A). Mice were also evaluated for body composition using NMR as described in Methods, and data show significant loss of fat mass in mice treated with either $50 / 12.5$ or $100 / 25 \mathrm{mg} / \mathrm{kg}$ lopinavir/ ritonavir (Fig. 1B). Specifically, 2-way ANOVA revealed significant main effects of duration $\left(\mathrm{F}_{(2,43)}=27.28, \mathrm{p}<0.0001\right)$ and treatment group $\left(\mathrm{F}_{(2,43)}=720.95\right.$, $\left.\mathrm{p}<0.0001\right)$, on fat composition, with also a significant interaction $\left(\mathrm{F}_{(2,43)}=5.975, \mathrm{p}=0.0003\right)$. Post-hoc analyses revealed significant decreases in body fat caused by both $50 / 12.5$ and 100/25 mg/ $\mathrm{kg}$ lopinavir/ritonavir when measured at either 10 or 20 days after treatment onset (Fig. 1B). To evaluate the loss of body and fat weight in these mice, food intake over the duration of 
treatment was measured (Fig. 1C), and data analyses revealed a significant main effect of treatment duration $\left(\mathrm{F}_{(2,15)}=17.78, \mathrm{p}<0.0001\right)$ and drug administration $\left(\mathrm{F}_{(2,15)}=11.28, \mathrm{p}=\right.$ $0.001)$, on food intake, with also a significant interaction $\left(\mathrm{F}_{(2,15)}=14.41, \mathrm{p}<0.0001\right)$. Posthoc analysis of food intake data revealed that only the $100 / 25 \mathrm{mg} / \mathrm{kg}$ dose of lopinavir/ ritonavir decreased food intake, and only after 20 days of treatment (Fig. C). These data indicate that the low dose of lopinavir/ritonavir administration reproduces a pattern of lipodystrophy in mice similar to that observed in human subjects prescribed PI, but that higher doses also cause significant weight loss that is likely compounded by decreased food intake.

\subsection{Effects of lopinavir/ritonavir on cognitive and motor performance}

To determine if PI-induced metabolic compromise was associated with neurologic impairment, both motor and cognitive functions were assessed. To ensure that the behavioral data reflected only the most direct effects of the PI drugs and were not confounded artificially by metabolic changes secondary to decreased food intake, only vehicle- and $50 / 12.5 \mathrm{mg} / \mathrm{kg}$ lopinavir/ritonavir-treated mice were included in behavioral analyses. Cognitive function was measured using the Stone T-maze maze after 3 weeks of lopinavir/ ritonavir exposure. The Stone maze is a task of procedural learning and memory has been used to evaluate cognitive impairments in rodents (Stranahan et al., 2008; Shukitt-Hale et al., 2008; Pistell et al., 2009, Pistell and Ingram, 2010). Furthermore, this task is very well suited for use in mice as it does not require the animals to swim, and is not confounded by changes in nociception, food-seeking behavior, or motor impairment (Pistell et al., 2010). By recording errors made across 15 training trials in this task, we observed that lopinavir/ ritonavir treatment resulted in significant cognitive impairment (Fig 2A). Specifically, ANOVA on errors committed by mice revealed significant main effects of trial number $\left(F_{(4,25)}=47.66, p<0.0001\right)$ and treatment group $\left(F_{(1,25)}=9.817, p=0.0044\right)$, with also a significant interaction $\left(\mathrm{F}_{(4,25)}=3.361, \mathrm{p}=0.0126\right)$. Post-hoc analyses revealed that 50/12.5 $\mathrm{mg} / \mathrm{kg}$ lopinavir/ritonavir-treated mice committed significantly more errors in the trial blocks 4-6, 7-9, and 10-12 as compared to vehicle-treated mice (Fig. 2A). The degree of impairment caused by lopinavir/ritonavir (approximately $70 \%$ increase in errors in trials 4 12 ) is greater than the degree of impairment caused by diet-induced obesity in mice (Pistell et al., 2010), but is roughly comparable to the degree of cognitive impairment noted in aged (25 month) mice compared to young (5-month) mice (D.K. Ingram and P.J. Pistell, unpublished observations). Finally, although naïve (i.e., not injected) mice were not included in this specific study, comparison of data obtained from vehicle-injected mice to published data obtained from control, un-manipulated C57BL/6 mice of the same age (Pistell and Ingram, 2010) does not suggest that the regimen of daily injections significantly affected Stone maze performance in vehicle-treated mice.

The rotarod is a very commonly used task for assessing motor ability in rodents, and measures the time the animal is able to remain on an accelerating rotating cylinder. Motor performance of vehicle- and 50/12.5 mg/kg lopinavir/ritonavir-treated mice was thus analyzed using the rotarod after 3 weeks of lopinavir/ritonavir exposure as described in Methods. Analysis of rotarod performance data did not reveal any impairment in motor function in 50/12.5 mg/kg lopinavir/ritonavir-treated mice as compared to vehicle-treated mice (Fig 2B).

\subsection{Effects of lopinavir/ritonavir on metabolic parameters}

As the PI drugs themselves are not blood-brain barrier permeable, aspects of metabolic syndrome were examined to begin to understand how administration of PI drugs disrupts cognition. To confirm that NMR-based measures of body composition indicated significant lipoatrophy, the retroperitoneal fat pad was isolated from all mice and weighed. Data show 
that lopinavir/ritonavir treatment caused significant differences in retroperitoneal fat pad mass between groups $\left(\mathrm{F}_{(43)}=31.08, \mathrm{p}<0.0001\right)$, and post-hoc analyses confirmed significant dose-dependent lipodystrophic effects of lopinavir/ritonavir (Fig. 3A). In addition to its function as an energy store, adipose tissue is well known to be an important player in the regulation of many biological processes through the secretion of adipokines (Frühbeck, 2008; Rocha and Libby, 2008). Over 50 adipokines have been identified, and generally function as hormones to influence energy homeostasis and feeding behavior (Ahima and Osei, 2008). However, certain adipokines, particularly adiponectin and leptin have been shown to have potentially important physiological effects in the brain (Harvey et al., 2005;Oomura et al., 2006;Harvey, 2007; Ouchi and Walsh, 2007;Chen et al., 2009). To thus determine if PI-induced loss of adipose tissue was associated with decreased circulating adipokines, levels of adiponectin and leptin were measured in vehicle- and lopinavir/ ritonavir-treated mice. Data show that lopinavir/ritonavir treatment caused significant decreases in circulating leptin $\left(\mathrm{F}_{(38)}=19.81, \mathrm{p}<0.0001\right.$; Fig. 3B $)$ and adiponectin $\left(\mathrm{F}_{(40)}=\right.$ $36.98, \mathrm{p}<0.0001$; Fig. 3C). Post-hoc analyses also revealed significant, dose-dependent effects of both 50 and $100 \mathrm{mg} / \mathrm{kg}$ doses of lopinavir/ritonavir on serum adipokines.

Lipodystrophy is also associated with dyslipidemia as adipose tissue serves as the normal repository for lipid storage, and adipose tissue loss leads to elevations in the circulation and tissue deposition of blood lipids (Heilbronn et al., 2004; Simha and Gang, 2009). Indeed, one of the most common and rapid effects of PI therapy in humans is significant hyperlipidemia, with specific increases in triglycerides, fatty acids, and cholesterol (Tsiodras et al., 2000; Green, 2002; Moyle, 2007). As these lipid mediators are associated with neurologic impairment in non HIV-infected individuals, studies next assessed the panel of bioactive serum lipids in lopinavir/ritonavir-treated mice. Data show that the 21 day lopinavir/ritonavir regimen caused significant alterations in total serum cholesterol (Fig. 4A), as well as triglycerides (Fig. 4B) and fatty acids (NEFA, Fig. 4C). Statistical analyses confirm significant differences between treatment groups in circulating cholesterol $\left(\mathrm{F}_{(43)}=\right.$ $5.225, \mathrm{p}=0.0095)$, triglycerides $\left(\mathrm{F}_{(36)}=5.386, \mathrm{p}=0.0093\right)$, and fatty acids $\left(\mathrm{F}_{(38)}=3.98, \mathrm{p}\right.$ $=0.0275)$. However, post-hoc analyses revealed that only triglycerides were significantly elevated by the low $50 \mathrm{mg} / \mathrm{kg}$ dose of lopinavir/ritonavir (Fig. 4B).

To determine if the PI-induced pattern of lipodystrophy and hyperlipidemia was associated with loss of glycemic control, blood glucose was measured throughout the duration of PI exposure, and insulin levels in serum were measured after 3 weeks of exposure. Data show that fasting blood glucose was not significantly altered at any time during exposure to daily lopinavir/ritonavir administration (Fig. 5A). However, data show that lopinavir/ritonavir did cause significant changes in serum insulin levels measured after the 21-day regimen (Fig. 5B). The 1-way ANOVA indicated significant differences in serum insulin between groups $\left(\mathrm{F}_{(23)}=4.13, \mathrm{p}=0.0307\right)$, but post-hoc analyses showed that only the $100 \mathrm{mg} / \mathrm{kg}$ dose significantly elevated insulin levels (Fig. 5B).

\section{DISCUSSION}

While HIV-1 most directly targets the host immune system, many HIV-infected individuals also exhibit a spectrum of neurologic disorders ranging from peripheral neuropathy to mild behavioral disturbances to overt dementia (reviewed in Ances and Ellis, 2007; Nath et al., 2008; Power et al., 2009). While estimates of the prevalence of dementia in the early 1990's approached $30 \%$, the widespread availability of combination ART has dramatically reduced the most severe forms of HIV-associated dementia (Sacktor et al., 2001). However, HIV remains the most common preventable and treatable cause of neurologic impairment in patients under 50 (Ances and Ellis, 2007), and epidemiological data suggest that the prevalence of HIV-associated neurocognitive disorders (HAND) have not been significantly 
reduced by ART intervention (McArthur et al., 2003; McArthur, 2004). For example, epidemiological evidence suggests that while only approximately $\sim 10 \%$ of HIV-positive suffer from HIV-associated dementia, near 30\% of HIV-1-positive individuals display more subtle manifestations of neurologic dysfunction (McArthur et al., 2003). As ART regimens are generally quite capable of maintaining low viral load, these data indicate that new mediators of neurologic dysfunction may have developed in the ART era. The results emerging from our study indicate that ART elements themselves, acting through the development of specific aspects of metabolic dysfunction, could be indirectly contributing to neurologic abnormalities in HIV-positive patients. While it is recognized that the metabolic effects of ART could contribute to premature atherosclerosis and cardiovascular risk in HIV patients, the potential effects of dyslipidemia on neurologic function in HIV patients have not been directly examined. However, recent reports indicate that HIV patients with metabolic compromise have a significantly greater risk of developing neurologic complications, including both cognitive and motor disturbances (Valcour et al., 2004, 2005, 2006, 2008). Collectively, available data show that ART can cause metabolic syndrome and in turn suggest that metabolic syndrome may participate in the development of neurologic and cognitive dysfunction.

While the exact physiologic mechanisms whereby ART-induced metabolic changes could alter cognition are not known, one of the most significant and early changes noted in this study of lopinavir/ritonavir-treated mice was the rapid and significant decline in total fat mass. This observation is in keeping with clinical observations of HIV patients, as the HIV FRAM study revealed that HIV-infected men with lipoatrophy had less peripheral and central subcutaneous adipose tissue (SAT) and also less visceral adipose tissue (VAT) (Bacchetti et al., 2005), contrary to the early impression that peripheral lipoatrophy is always accompanied by central fat accumulation. Although protease inhibitors are thought to participate in ART-related disruptions to adipose (reviewed in Flint et al., 2009), the development of lipodystrophy is also associated with nucleoside reverse transcriptase inhibitors (NRTIs) particularly stavudine and zidovudine, which are well known to disrupt adipose physiology via the induction of mitochondrial dysfunction (Villaroya et al., 2005; Caron-Debarle et al., 2010). While the nature of the link between lipoatrophy and brain function has not been well studied, it is becoming understood that adipose tissue is an important factor in the regulation of many pathological processes via the secretion of adipokines (Frühbeck, 2008; Rocha and Libby, 2008; Ahima and Osei, 2008). Data in this manuscript show that the adipokines adiponectin and leptin were significantly and dosedependently reduced by lopinavir/ritonavir treatment, and these specific adipose-released signals have been shown to have potentially important physiological effects in the brain (Harvey et al., 2005; Oomura et al., 2006; Harvey, 2007; Ouchi and Walsh, 2007; Chen et al;, 2009). While leptin is best known as an afferent adiposity signal to the brain that suppresses appetite and increases energy expenditure (Friedman and Halaas, 1998), leptin receptors (OBR) are widely expressed in numerous extra-hypothalamic regions of the brain, including the hippocampus, cerebellum, amygdala, and brain stem (Elmquist et al., 1998; Tartaglia et al., 1995; Fei et al., 1997). Studies have also identified a role for leptin in cognitive processes (reviewed in Harvey et al., 2005; White et al., 2009). For example, direct administration of leptin into the dentate gyrus has been shown to enhance long term potentiation (Wayner et al., 2004), and intravenous administration of leptin can facilitate the behavioral performance of rats in passive avoidance and Morris water-maze tasks (Oomura et al., 2006). Finally, leptin has been shown to modulate inflammatory signaling in microglia (Pinteaux et al., 2007; Tang et al., 2007) which could affect brain inflammatory and oxidative pathways. Likewise, adiponectin is significantly decreased in HIV-positive patients with lipodystrophy (Kinlaw and Marsh, 2004; Barbaro, 2007), and has well-known anti-inflammatory affects (Ouchi and Walsh, 2007 that have been shown to be neuroprotective (Jung et al., 2006; Chen et al., 2009). 
Lipodystrophy can also lead to significant disruption in the circulation and tissue deposition of blood lipids (Heilbronn et al., 2004; Simha and Garg, 2008). Indeed, one of the most common and rapid effects of PI therapy in humans is significant hyperlipidemia, with specific increases in triglycerides, fatty acids, and cholesterol (Tsiodras et al;, 2000; Green, 2002; Moyle, 2007). Data presented in this manuscript show that combined lopinavir/ ritonavir treatment reproduces this pattern of hyperlipidemia in mice. However, it is not clear whether lopinavir or ritonavir, or the combination of both, is ultimately responsible for triggering the chain of events leading to metabolic and cognitive dysfunction. Ritonavir is included in ART formulations not for its own antiviral activity, but because it profoundly boosts the action of other PIs via inhibition of hepatic cytochrome P450-3A4 activity (Merry et al., 1997). Indeed, this discovery has led to dramatic improvements in PI efficacy, but also has resulted in adverse effects related to altered metabolism of medications and/or food additives. Thus, it is possible that ritonavir could have disrupted metabolism of the ethanol and propylene glycol components of the vehicle, or even altered bile acid metabolism (Bodin et al., 2005), leading to alterations in the metabolism of dietary lipids. While elevated serum lipids might disrupt cognitive function directly via disruptions to cerebrovascular perfusion, many studies have examined the role of serum cholesterol in brain function independent of vascular effects. In general, results are mixed, with some studies noting a correlation between cholesterol levels and cognitive function, whereas other studies do not (Reitz et al., 2005; Rogers et al., 1989; Atzmon et al., 2002).

Alternatively, hypertriglyceridemia is perhaps the most frequent and severe metabolic manifestation of PI therapy in humans (Tsiodras et al., 2000; Green, 2002; Moyle, 2007), and data reported in this manuscript shows that triglycerides and fatty acids were increased by lopinavir/ritonavir to a greater degree than cholesterol. Furthermore, triglycerides were significantly increased by the low dose of lopinavir/ritonavir that also affected cognition, while higher doses of lopinavir/ritonavir were necessary to increase cholesterol and insulin levels significantly over levels in vehicle-treated mice. Triglycerides and free fatty acids are well known to initiate toxic, oxidant-based signaling in the vascular endothelium (Hennig et al., 2001), but interestingly, there is compelling evidence that triglycerides and/or free fatty acids might mediate CNS dysfunction. For example, it has been shown that direct administration of triglycerides can impair hippocampal long-term potentiation, and that lowering triglycerides pharmacologically with gemfibrozil reduces the expression of markers of oxidative stress in the brains of obese mice (Farr et al., 2008). These studies are further supported by clinical studies in which it has been shown that elevated triglycerides are associated with poor cognitive performance in patients with type 2 diabetes (Perlmuter et al., 1998), and by studies in which the reduction of hypertriglyceridemia with gemfibrozil improved cerebral blood flow and function on the cognitive capacity screening examination (Rogers et al., 1989). Finally, triglycerides have been shown to impair leptin transport through the blood-brain barrier (Banks et al., 2004), indicating that the well-characterized phenomena of leptin resistance with age or obesity may be related in part to the action of triglycerides at the blood-brain barrier. Another potential means whereby triglycerides could adversely affect the brain is through their breakdown into free fatty acids, which can also be formed and released directly from adipocytes in setting of lipoatrophy. GPR40, a putative free fatty acid receptor, has been localized to the hippocampus (Ma et al., 2008), and the saturated free fatty acids palmitic acid and lauric acid have both been shown to cause inflammatory signaling in cultured macrophages (Laine et al., 2007; Aronis et al., 2008), and also to modulate astrocytic and microglial signaling (Patil and Chan, 2005).

\section{CONCLUSIONS}

Our results confirm that lopinavir/ritonavir administration causes significant metabolic dysfunction, including significant lipoatrophy and dose-dependent patterns of 
hypoadiponectinemia, hypoleptinemia, hyperlipidemia, and hyperinsulinemia. These data are in keeping with published studies that have reported significant metabolic dysfunction in C57BL/6 mice treated with combined lopinavir/ritonavir in similar dose ranges (Prot et al., 2006). However, the most significant finding of this study is that even the lowest dose of lopinavir/ritonavir caused significant cognitive impairment in mice. Thus, these data show that HIV protease inhibitors can cause cognitive as well as metabolic impairment, and suggest that the development metabolic dysfunction in HIV patients might contribute significantly to HIV-associated neurocognitive decline. These data are consistent with a new but growing body of literature describing the sensitivity of the brain to metabolic dysfunction (reviewed in (Bruce-Keller et al., 2009). The relationship between metabolic dysfunction and cognitive impairment has been documented in humans (Elias et al., 2003, 2005; Waldstein and Katzel, 2006), as well as in experimental animal studies (Baran et al., 2005; Winocur and Greenwood, 2005; Granholm et al., 2008; White et al., 2009; Pistell et al., 2010). Collectively, results from this study reinforce the link between metabolic dysfunction and cognitive loss, and suggest that sustained metabolic dysfunction in HIV patients could potentially participate in the pathogenesis of HAND.

\section{Acknowledgments}

The authors are grateful to Dr. Barry Robert for expert veterinary assistance and discussion of lopinavir/ritonavir administration. This work was supported by grants from the NIH (NS46267 and AG05119), and also used PBRC Core facilities (Animal Phenotyping) that are funded by the NIH (P20-RR021945 and P30-DK072476).

\section{References}

Ahima RS, Osei SY. Adipokines in obesity. Front Horm Res 2008;36:182-197. [PubMed: 18230903]

Ances BM, Ellis RJ. Dementia and neurocognitive disorders due to HIV-1 infection. Semin Neurol 2007;27:86-92. [PubMed: 17226745]

Anuurad E, Semrad A, Berglund L. Human immunodeficiency virus and highly active antiretroviral therapy-associated metabolic disorders and risk factors for cardiovascular disease. Metab Syndr Relat Disord 2009;7:401-410. [PubMed: 19355810]

Aronis A, Madar Z, Tirosh O. Lipotoxic effects of triacylglycerols in J774.2 macrophages. Nutrition 2008;24:167-176. [PubMed: 18165129]

Atzmon G, Gabriely I, Greiner W, Davidson D, Schechter C, Barzilai N. Plasma HDL levels highly correlate with cognitive function in exceptional longevity. J Gerontol Med Sci 2002;57:M712M715.

Bacchetti P, Gripshover B, Grunfeld C, Heymsfield S, McCreath H, Osmond D, Saag M, Scherzer R, Shlipak M, Tien P. (FRAM). Fat distribution in men with HIV infection. J Acquir Immune Defic Syndr 2005;40:121-131. [PubMed: 16186728]

Bandaru VV, McArthur JC, Sacktor N, Cutler RG, Knapp EL, Mattson MP, Haughey NJ. Associative and predictive biomarkers of dementia in HIV-1-infected patients. Neurology 2007;68:1481-1487. [PubMed: 17470750]

Banks WA, Coon AB, Robinson SM, Moinuddin A, Shultz JM, Nakaoke R, Morley JE. Triglycerides induce leptin resistance at the blood-brain barrier. Diabetes 2004;53:1253-1260. [PubMed: 15111494]

Baran SE, Campbell AM, Kleen JK, Foltz CH, Wright RL, Diamond DM, Conrad CD. Combination of high fat diet and chronic stress retracts hippocampal dendrites. Neuroreport 2005;16:39-43. [PubMed: 15618887]

Barbaro G. Visceral fat as target of highly active antiretroviral therapy-associated metabolic syndrome. Curr Pharm Des 2007;13:2208-2213. [PubMed: 17627554]

Bodin K, Lindbom U, Diczfalusy U. Novel pathways of bile acid metabolism involving CYP3A4. Biochim Biophys Acta 2005;1687:84-93. [PubMed: 15708356]

Bruce-Keller AJ, Keller JN, Morrison CD. Obesity and vulnerability of the CNS. Biochim Biophys Acta 2009;1792:395-400. [PubMed: 18992327] 
Caron-Debarle M, Lagathu C, Boccara F, Vigouroux C, Capeau J. HIV-associated lipodystrophy: from fat injury to premature aging. Trends Mol Med 2010;16:218-229. [PubMed: 20400373]

Cespedes MS, Aberg JA. Neuropsychiatric complications of antiretroviral therapy. Drug Saf 2006;29:865-874. [PubMed: 16970510]

Chandwani A, Shuter J. Lopinavir/ritonavir in the treatment of HIV-1 infection: a review. Ther Clin Risk Manag 2008;4:1023-1033. [PubMed: 19209283]

Chen B, Liao WQ, Xu N, Xu H, Wen JY, Yu CA, Liu XY, Li CL, Zhao SM, Campbell W. Adiponectin protects against cerebral ischemia-reperfusion injury through anti-inflammatory action. Brain Res 2009;1273:129-137. [PubMed: 19362080]

Cvetkovic RS, Goa KL. Lopinavir/ritonavir: a review of its use in the management of HIV infection. Drugs 2003;63:769-802. [PubMed: 12662125]

De Luca A, Ciancio BC, Larussa D, Murri R, Cingolani A, Rizzo MG, Giancola ML, Ammassari A, Ortona L. Correlates of independent HIV-1 replication in the CNS and of its control by antiretrovirals. Neurology 2002;59:342-347. [PubMed: 12177366]

Elias MF, Elias PK, Sullivan LM, Wolf PA, D’Agostino RB. Lower cognitive function in the presence of obesity and hypertension: the Framingham Heart Study. Int J Obes Relat Metab Disord 2003;27:260-268. [PubMed: 12587008]

Elias MF, Elias PK, Sullivan LM, Wolf PA, D’Agostino RB. Obesity, diabetes and cognitive deficit: the Framingham Heart Study. Neurobiol Aging 2005;26:11-16. [PubMed: 16223549]

Elmquist JK, Bjorbaek C, Ahima RS, Flier JS, Saper CB. Distributions of leptin receptor mRNA isoforms in the rat brain. J Comp Neurol 1998;395:535-547. [PubMed: 9619505]

Farr SA, Yamada KA, Butterfield DA, Abdul HM, Xu L, Miller NE, Banks WA, Morley JE. Obesity and hypertriglyceridemia produce cognitive impairment. Endocrinology 2008;149:2628-2636. [PubMed: 18276751]

Fei H, Okano HJ, Li C, Lee GH, Zhao C, Darnell R, Friedman JM. Anatomic localization of alternatively spliced leptin receptors $(\mathrm{Ob}-\mathrm{R})$ in mouse brain and other tissues. Proc Natl Acad Sci USA 1997;94:7001-7005. [PubMed: 9192681]

Flint OP, Noor MA, Hruz PW, Hylemon PB, Yarasheski K, Kotler DP, Parker RA, Bellamine A. The role of protease inhibitors in the pathogenesis of HIV-associated lipodystrophy: cellular mechanisms and clinical implications. Toxicol Pathol 2009;37:65-77. [PubMed: 19171928]

Friedman JM, Halaas JL. Leptin and the regulation of body weight in mammals. Nature 1998;395:763-770. [PubMed: 9796811]

Frühbeck G. Overview of adipose tissue and its role in obesity and metabolic disorders. Methods Mol Biol 2008;456:1-22. [PubMed: 18516549]

Granholm AC, Bimonte-Nelson HA, Moore AB, Nelson ME, Freeman LR, Sambamurti K. Effects of a saturated fat and high cholesterol diet on memory and hippocampal morphology in the middleaged rat. J Alzheimers Dis 2008;14:133-145. [PubMed: 18560126]

Green ML. Evaluation and management of dyslipidemia in patients with HIV infection. J Gen Intern Med 2002;17:797-810. [PubMed: 12390557]

Harvey J. Leptin regulation of neuronal excitability and cognitive function. Curr Opin Pharmacol 2007;7:643-647. [PubMed: 18024215]

Harvey J, Shanley LJ, O’Malley D, Irving AJ. Leptin: a potential cognitive enhancer? Biochem. Soc Trans 2005;33:1029-1032.

Heilbronn L, Smith SR, Ravussin E. Failure of fat cell proliferation, mitochondrial function and fat oxidation results in ectopic fat storage, insulin resistance and type II diabetes mellitus. Int J Obes Relat Metab Disord 2004;28(Suppl 4):S12-S21. [PubMed: 15592481]

Hennig B, Toborek M, McClain CJ. High-energy diets, fatty acids and endothelial cell function: implications for atherosclerosis. J Am Coll Nutr 2001;20:97-105. [PubMed: 11349944]

Herman JS, Easterbrook PJ. The metabolic toxicities of antiretroviral therapy. Int J STD AIDS 2001;12:555-562. [PubMed: 11516363]

Hurwitz BE, Klimas NG, Llabre MM, Maher KJ, Skyler JS, Bilsker MS, McPherson-Baker S, Lawrence PJ, Laperriere AR, Greeson JM, Klaus JR, Lawrence R, Schneiderman N. HIV, metabolic syndrome $\mathrm{X}$, inflammation, oxidative stress, and coronary heart disease risk: role of protease inhibitor exposure. Cardiovasc Toxicol 2004;4:303-316. [PubMed: 15470277] 
Jiang B, Hebert VY, Khandelwal AR, Stokes KY, Dugas TR. HIV-1 antiretrovirals induce oxidant injury and increase intima-media thickness in an atherogenic mouse model. Toxicol Lett 2009;187:164-171. [PubMed: 19429260]

Jung TW, Lee JY, Shim WS, Kang ES, Kim JS, Ahn CW, Lee HC, Cha BS. Adiponectin protects human neuroblastoma SH-SY5Y cells against MPP+-induced cytotoxicity. Biochem Biophys Res Commun 2006;343:564-570. [PubMed: 16554029]

Kinlaw WB, Marsh B. Adiponectin and HIV-lipodystrophy: taking HAART. Endocrinology 2004;145:484-486. [PubMed: 14739152]

Laine PS, Schwartz EA, Wang Y, Zhang WY, Karnik SK, Musi N, Reaven PD. Palmitic acid induces IP-10 expression in human macrophages via NF-kappaB activation. Biochem Biophys Res Commun 2007;358:150-155. [PubMed: 17467667]

Lenhard JM, Croom DK, Weiel JE, Spaltenstein A, Reynolds DJ, Furfine ES. Dietary fat alters HIV protease inhibitor-induced metabolic changes in mice. J Nutr 2000a;130:2361-2366. [PubMed: 10958836]

Lenhard JM, Croom DK, Weiel JE, Winegar DA. HIV protease inhibitors stimulate hepatic triglyceride synthesis. Arterioscler Thromb Vasc Biol 2000b;20:2625-2629. [PubMed: 11116063]

Lenhard JM, Furfine ES, Jain RG, Ittoop O, Orband-Miller LA, Blanchard SG, Paulik MA, Weiel JE. HIV protease inhibitors block adipogenesis and increase lipolysis in vitro. Antiviral Res 2000c; 47:121-129. [PubMed: 10996400]

Ma D, Lu L, Boneva NB, Warashina S, Kaplamadzhiev DB, Mori Y, Nakaya MA, Kikuchi M, Tonchev AB, Okano H, Yamashima T. Expression of free fatty acid receptor GPR40 in the neurogenic niche of adult monkey hippocampus. Hippocampus 2008;18:326-333. [PubMed: 18064707]

McArthur JC. HIV dementia: an evolving disease. J Neuroimmunol 2004;157:3-10. [PubMed: 15579274]

McArthur JC, Haughey N, Gartner S, Conant K, Pardo C, Nath A, Sacktor N. Human immunodeficiency virus-associated dementia: an evolving disease. J Neurovirol 2003;9:205-221. [PubMed: 12707851]

Merry C, Barry MG, Mulcahy F, Ryan M, Heavey J, Tjia JF, Gibbons SE, Breckenridge AM, Back DJ. Saquinavir pharmacokinetics alone and in combination with ritonavir in HIV-infected patients. AIDS 1997;11:F29-33. [PubMed: 9084785]

Moyle G. Metabolic issues associated with protease inhibitors. J Acquir Immune Defic Syndr 2007;45(Suppl 1):S19-26. [PubMed: 17525687]

Nath A, Schiess N, Venkatesan A, Rumbaugh J, Sacktor N, McArthur J. Evolution of HIV dementia with HIV infection. Int Rev Psychiatry 2008:25-31. [PubMed: 18240060]

Oomura Y, Hori N, Shiraishi T, Fukunaga K, Takeda H, Tsuji M, Matsumiya T, Ishibashi M, Aou S, Li X, Kohno D, Uramura K, Sougawa H, Yada T, Wayner M, Sasaki K. Leptin facilitates learning and memory performance and enhances hippocampal CA1 long-term potentiation and CaMK II phosphorylation in rats. Peptides 2006;11:2738-2749. [PubMed: 16914228]

Ouchi N, Walsh K. Adiponectin as an anti-inflammatory factor. Clin Chim Acta 2007;380:24-30. [PubMed: 17343838]

Patel K, Ming X, Williams PL, Robertson KR, Oleske JM, Seage GR. International Maternal Pediatric Adolescent AIDS Clinical Trials 219/219C Study Team Team. Impact of HAART and CNSpenetrating antiretroviral regimens on HIV encephalopathy among perinatally infected children and adolescents. AIDS 2006;23:1893-1901. [PubMed: 19644348]

Patil S, Chan C. Palmitic and stearic fatty acids induce Alzheimer-like hyperphosphorylation of tau in primary rat cortical neurons. Neurosci Lett 2005;384:288-293. [PubMed: 15939536]

Perlmuter LC, Nathan DM, Goldfinger SH, Russo PA, Yates J, Larkin M. Triglyceride levels affect cognitive function in non-insulin-dependent diabetes. J Diabetes Complications 1998;2:210-213.

Pinkel D. The use of body surface area as a criterion of drug dosage in cancer chemotherapy. Cancer Res 1958;18:853-856. [PubMed: 13573353]

Pinteaux E, Inoue W, Schmidt L, Molina-Holgado F, Rothwell NJ, Luheshi GN. Leptin induces interleukin-1 beta release from rat microglial cells through a caspase 1 independent mechanism. J Neurochem 2007;102:826-833. [PubMed: 17419800] 
Pistell PJ, Ingram DK. Development of a water-escape motivated version of the Stone T-maze for mice. Neuroscience 2010;166:61-72. [PubMed: 20026250]

Pistell PJ, Morrison CD, Gupta S, Knight AG, Keller JN, Ingram DK, Bruce-Keller AJ. Cognitive impairment following high fat diet consumption is associated with brain inflammation. $\mathrm{J}$ Neuroimmunol 2010;219:25-32. [PubMed: 20004026]

Pistell PJ, Nelson CM, Miller MG, Spangler EL, Ingram DK, Devan BD. Striatal lesions interfere with acquisition of a complex maze task in rats. Behav Brain Res 2009;197:138-143. [PubMed: 18789359]

Power C, Boissé L, Rourke S, Gill MJ. NeuroAIDS: an evolving epidemic. Can J Neurol Sci 2009;36:285-295. [PubMed: 19534327]

Prot M, Heripret L, Cardot-Leccia N, Perrin C, Aouadi M, Lavrut T, Garraffo R, Dellamonica P, Durant J, Le Marchand-Brustel Y, Binétruy B. Long-term treatment with lopinavir-ritonavir induces a reduction in peripheral adipose depots in mice. Antimicrob Agents Chemother 2006;50:3998-4004. [PubMed: 17000748]

Quinn TC. HIV epidemiology and the effects of antiviral therapy on long-term consequences. AIDS Patient Care STDS 2008;22(Suppl 3):S7-12.

Reagan-Shaw S, Nihal M, Ahmad N. Dose translation from animal to human studies revisited. Faseb J 2007;22:659-661. [PubMed: 17942826]

Reitz C, Luchsinger J, Tang M, Manly J, Mayeux R. Impact of plasma lipids and time on memory performance in healthy elderly without dementia. Neurology 2005;64:1378-1383. [PubMed: 15851727]

Rocha VZ, Libby P. The multiple facets of the fat tissue. Thyroid 2008;18:175-183. [PubMed: 18279018]

Rogers RL, Meyer JS, McClintic K, Mortel KF. Reducing hypertriglyceridemia in elderly patients with cerebrovascular disease stabilizes or improves cognition and cerebral perfusion. Angiology 1989;40:260-269. [PubMed: 2705633]

Sacktor N, Lyles RH, Skolasky R, Kleeberger C, Selnes OA, Miller EN, Becker JT, Cohen B, McArthur JC. Study., MAC. HIV-associated neurologic disease incidence changes:: Multicenter AIDS Cohort Study, 1990-1998. Neurology 2001;56:257-260. [PubMed: 11160967]

Sawyer M, Ratain MJ. Body surface area as a determinant of pharmacokinetics and drug dosing. Invest New Drugs 2001;19:171-177. [PubMed: 11392451]

Schambelan M, Benson CA, Carr A, Currier JS, Dubé MP, Gerber JG, Grinspoon SK, Grunfeld C, Kotler DP, Mulligan K, Powderly WG, Saag MS. Management of metabolic complications associated with antiretroviral therapy for HIV-1 infection: recommendations of an International AIDS Society-USA panel. J Acquir Immune Defic Syndr 2002;31:257-275. [PubMed: 12439201]

Shukitt-Hale B, Lau FC, Carey AN, Galli RL, Spangler EL, Ingram DK, Joseph JA. Blueberry polyphenols attenuate kainic acid-induced decrements in cognition and alter inflammatory gene expression in rat hippocampus. Nutr Neurosci 2008;11:172-182. [PubMed: 18681986]

Simha V, Garg A. Inherited lipodystrophies and hypertriglyceridemia. Curr Opin Lipidol 2009;20:300-308. [PubMed: 19494770]

Stranahan AM, Lee K, Pistell PJ, Nelson CM, Readal N, Miller MG, Spangler EL, Ingram DK, Mattson MP. Accelerated cognitive aging in diabetic rats is prevented by lowering corticosterone levels. Neurobiol Learn Mem 2008;90:479-483. [PubMed: 18579418]

Tang CH, Lu DY, Yang RS, Tsai HY, Kao MC, Fu WM, Chen YF. Leptin-induced IL-6 production is mediated by leptin receptor, insulin receptor substrate-1, phosphatidylinositol 3-kinase, Akt, NFkappaB, and p300 pathway in microglia. J Immunol 2007;179:1292-1302. [PubMed: 17617622]

Tartaglia LA, Dembski M, Weng X, Deng N, Culpepper J, Devos R, Richards GJ, Campfield LA, Clark FT, Deeds J, Muir C, Sanker S, Moriarty A, Moore KJ, Smutko JS, Mays GG, Wool EA, Monroe CA, Tepper RI. Identification and expression cloning of a leptin receptor. OB-R Cell 1995;83:1263-1271.

Thomas CM, Smart EJ. How HIV protease inhibitors promote atherosclerotic lesion formation. Curr Opin Lipidol 2007;18:561-565. [PubMed: 17885428] 
Tsiodras S, Mantzoros C, Hammer S, Samore M. Effects of protease inhibitors on hyperglycemia, hyperlipidemia, and lipodystrophy: a 5-year cohort study. Arch Intern Med 2000;160:2050-2056. [PubMed: 10888979]

Valcour V, Watters MR, Williams AE, Sacktor N, McMurtray A, Shikuma C. Aging exacerbates extrapyramidal motor signs in the era of highly active antiretroviral therapy. J Neurovirol 2008;14:362-367. [PubMed: 18989814]

Valcour VG, Sacktor NC, Paul RH, Watters MR, Selnes OA, Shiramizu BT, Williams AE, Shikuma CM. Insulin resistance is associated with cognition among HIV-1-infected patients: the Hawaii Aging With HIV cohort. J Acquir Immune Defic Syndr 2006;43:405-410. [PubMed: 17099311]

Valcour VG, Shikuma CM, Shiramizu BT, Williams AE, Watters MR, Poff PW, Grove JS, Selnes OA, Sacktor NC. Diabetes, insulin resistance, and dementia among HIV-1-infected patients. J Acquir Immune Defic Syndr 2005;38:31-36. [PubMed: 15608521]

Valcour VG, Shikuma CM, Watters MR, Sacktor NC. Cognitive impairment in older HIV-1seropositive individuals: prevalence and potential mechanisms. AIDS Patient Care STDS 2004;18(Suppl 1):S79-86.

Villarroya F, Domingo P, Giralt M. Lipodystrophy associated with highly active anti-retroviral therapy for HIV infection: the adipocyte as a target of anti-retroviral-induced mitochondrial toxicity. Trends Pharmacol Sci 2005;26:88-93. [PubMed: 15681026]

Waldstein SR, Katzel LI. Interactive relations of central versus total obesity and blood pressure to cognitive function. Int J Obes (Lond) 2006;30:201-207. [PubMed: 16231030]

Wayner MJ, Armstrong DL, Phelix CF, Oomura Y. Orexin-A (Hypocretin-1) and leptin enhance LTP in the dentate gyrus of rats in vivo. Peptides 2004;25:991-996. [PubMed: 15203246]

White CL, Pistell PJ, Purpera MN, Gupta S, Fernandez-Kim SO, Hise TL, Keller JN, Ingram DK, Morrison CD, Bruce-Keller AJ. Effects of high fat diet on Morris maze performance, oxidative stress, and inflammation in rats: contributions of maternal diet. Neurobiol Dis 2009;35:3-13. [PubMed: 19374947]

White CL, Purpera MN, Morrison CD. Maternal obesity is necessary for programming effect of a high-fat diet on offspring Am. J Physiol Regul Integr Comp Physiol 2009;296:464-472.

Winocur G, Greenwood CE. Studies of the effects of high fat diets on cognitive function in a rat model. Neurobiol Aging 2005;26:46-49. [PubMed: 16219391] 


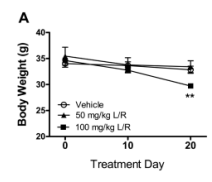

B
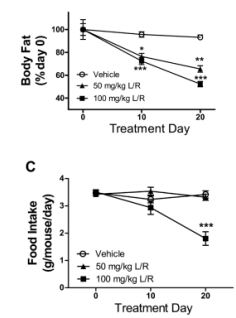

Figure 1. Lopinavir/ritonavir alters body weight and body composition in mice Male C57BL/6 mice were treated daily with vehicle (open circles), $50 \mathrm{mg}$ lopinavir/ $12.5 \mathrm{mg}$ ritonavir $/ \mathrm{kg}$ (50 mg/kg L/R, closed triangles), or 100mg lopinavir $/ 25 \mathrm{mg}$ ritonavir $/ \mathrm{kg}$ (100 $\mathrm{mg} / \mathrm{kg} \mathrm{L} / \mathrm{R}$, closed squares) and were evaluated regularly for (A) body weight; (B) total body fat mass expressed as percent fat mass measured at day 0 ; and (C) food intake. All data are mean and S.E.M. of 9-18 mice per group. Data were analyzed by 2-way ANOVA, and $*, * *$, and $* * *$ indicate significant $(\mathrm{p}<0.05, \mathrm{p}<0.01$, and $\mathrm{p}<0.001$, respectively) differences noted in lopinavir/ritonavir-treated mice as compared to vehicle-treated mice at the same timepoint. 


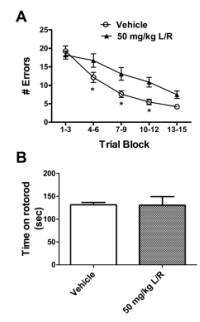

Figure 2. Lopinavir/ritonavir disrupts cognitive but not motor ability in mice Male C57BL/6 mice were treated daily with lopinavir/ritonavir (50mg lopinavir/12.5 mg ritonavir/kg body weight) for 21 days and then tested behaviorally. (A) Effects of lopinavir/ ritonavir on the number of errors committed over 15 trials of maze training. Data are means \pm S.E.M. of average errors accrued over 3-trial blocks and were generated from 9-18 mice per group. Data were analyzed by 2 -way ANOVA, and $*$ indicates significant $(\mathrm{p}<0.05)$ increases in errors made by lopinavir/ritonavir-treated mice. (C) Effects of lopinavir/ ritonavir on time mice were able to remain on an accelerating rotarod. Data are means \pm S.E.M. of average time on the rod measured over 3 trails. 
A

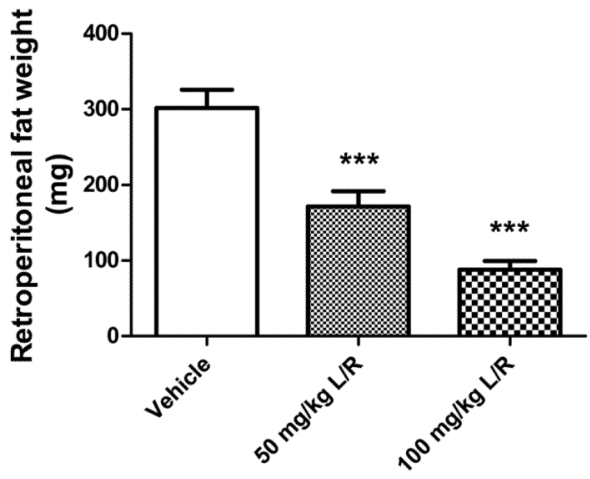

B


Figure 3. Lopinavir/ritonavir decreases retroperitoneal fat mass and circulating adipokines in mice

Male C57BL/6 mice were treated daily with vehicle, $50 \mathrm{mg}$ lopinavir/12.5 $\mathrm{mg}$ ritonavir/kg (50 mg/kg L/R), or 100mg lopinavir/25 mg ritonavir/kg (100 mg/kg L/R). After 21 days, mice were euthanatized and fat pads and sera were collected. (A) Effects of lopinavir/ ritonavir on the mass of the retroperitoneal fat pad. Data are means \pm S.E.M. of fat pad mass in milligrams, and were generated from 9-18 mice per group. Data were analyzed by 1-way ANOVA, and $* * *$ indicates significant $(\mathrm{p}<0.001)$ decreases in mass in lopinavir/ritonavirtreated mice as compared to vehicle-treated mice. (B) Effects of lopinavir/ritonavir on serum leptin concentration. Data are means \pm S.E.M. of leptin expressed as $\mathrm{ng} / \mathrm{ml}$ serum, and were generated from 9-18 mice per group. Data were analyzed by 1-way ANOVA, and ** and $* * *$ indicate significant ( $\mathrm{p}>0.01$ and $\mathrm{p}<0.001$, respectively) decreases in leptin in lopinavir/ 
ritonavir-treated mice as compared to vehicle-treated mice. (C) Effects of lopinavir/ritonavir on serum adiponectin concentration. Data are means \pm S.E.M. of adiponectin expressed as $\mathrm{ng} / \mu \mathrm{l}$ serum, and were generated from 9-18 mice per group. Data were analyzed by 1-way ANOVA, and $* * *$ indicates significant $(\mathrm{p}<0.001)$ decreases in adiponectin in lopinavir/ ritonavir-treated mice as compared to vehicle-treated mice. 
A

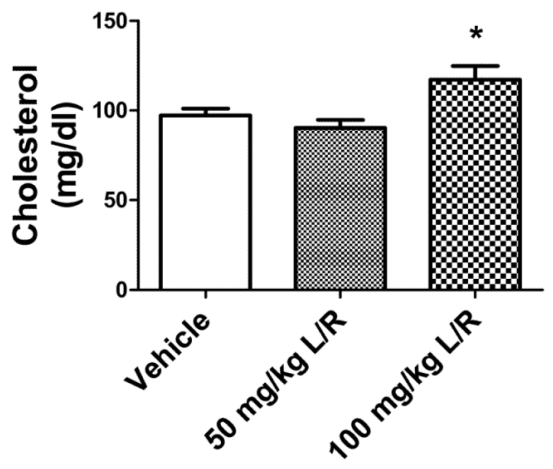

B
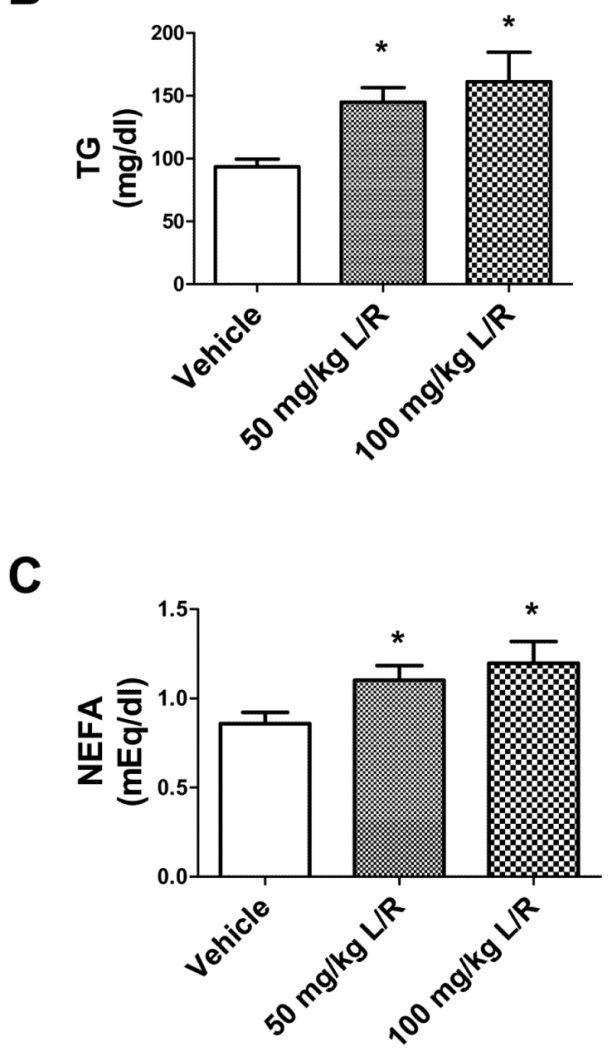

Figure 4. Lopinavir/ritonavir significantly increases circulating serum lipids in mice Male C57BL/6 mice were treated daily with vehicle, $50 \mathrm{mg}$ lopinavir/12.5 mg ritonavir/ $\mathrm{kg}$ (50 mg/kg L/R), or 100mg lopinavir/25 mg ritonavir/kg (100 mg/kg L/R). After 21 days, mice were euthanatized and serum was collected. (A) Effects of lopinavir/ritonavir on total serum cholesterol. Data are means \pm S.E.M. of cholesterol expressed as $\mathrm{mg} / \mathrm{dl}$ serum, and were generated from 9-18 mice per group. Data were analyzed by 1-way ANOVA, and * indicates a significant $(\mathrm{p}<0.05)$ increase in total cholesterol levels in mice treated with $100 \mathrm{mg}$ lopinavir/25 mg ritonavir/kg mice as compared to levels in vehicle-treated mice. (B) Effects of lopinavir/ritonavir on serum triglyceride (TG) concentration. Data are means \pm S.E.M. of triglycerides expressed as $\mathrm{mg} / \mathrm{dl}$ serum, and were generated from 9-18 mice per 
group. Data were analyzed by 1-way ANOVA, and * indicates significant ( $\mathrm{p}>0.05)$ increases in triglycerides in lopinavir/ritonavir-treated mice as compared to vehicle-treated mice. (C) Effects of lopinavir/ritonavir on serum fatty acids (NEFA). Data are means \pm S.E.M. of nonesterified fatty acids expressed as $\mathrm{mEq} / \mathrm{dl}$ serum, and were generated from 918 mice per group. Data were analyzed by 1 -way ANOVA, and * indicates significant ( $p>$ 0.05 ) increases in serum fatty acids in lopinavir/ritonavir-treated mice as compared to vehicle-treated mice. 



Figure 5. Lopinavir/ritonavir does not affect blood glucose in mice

(A) Male C57BL/6 mice were treated daily with vehicle (open circles), $50 \mathrm{mg}$ lopinavir/12.5 $\mathrm{mg}$ ritonavir/ $\mathrm{kg}$ (50 mg/kg L/R, closed triangles), or 100mg lopinavir/25 mg ritonavir/kg (100 mg/kg L/R, closed squares) and were evaluated regularly for blood glucose as described in Methods. Data are mean and S.E.M. of blood glucose expressed as $\mathrm{mg} / \mathrm{dl}$ of serum, and were generated from 9-18 mice per group. (B) Effects of lopinavir/ritonavir on serum insulin. Male C57BL/6 mice were treated daily with vehicle, $50 \mathrm{mg}$ lopinavir/12.5 mg ritonavir/ $\mathrm{kg}$ (50 mg/kg L/R), or 100mg lopinavir/25 mg ritonavir/kg (100 mg/kg L/R). After 21 days, mice were euthanatized and serum was collected, and insulin levels were determined using ELISA as described in Methods. Data are means \pm S.E.M. of insulin expressed as $\mathrm{ng} / \mathrm{ml}$ serum, and were generated from 9-18 mice per group. Data were analyzed by 1-way ANOVA, and * indicates significant ( $p>0.05)$ increases in serum insulin in mice treated with $100 \mathrm{mg}$ lopinavir/25 mg ritonavir/ $\mathrm{kg}$ as compared to vehicle-treated mice. 


\section{Table 1}

\section{Serum and brain lopinavir levels following injection}

Male C57BL/6 mice were treated with increasing doses of combined lopinavir/ritonavir, and serum and brain levels of lopinavir were measured by UPLC-MRM-MS exactly 4 hours after drug administration as described in Methods. Lopinavir levels were also measured in brains of mice that had been treated daily with lopinavir/ ritonavir for 21 days, but had recovered for 24 following their last injection (Brain Lopinavir (24hs)). Data are presented as $\mu \mathrm{g}$ lopinavir/ml serum and $\mu \mathrm{g}$ lopinavir/mg wet weight of brain, and are mean and STD of 2-4 mice per group.

\begin{tabular}{|c|c|c|c|}
\hline Treatment & Serum Lopinavir $(\boldsymbol{\mu g} / \mathbf{m l})$ & Brain Lopinavir $(\boldsymbol{\mu g} / \mathbf{g m})$ & Brain Lopinavir $(\mathbf{2 4 h s )}(\boldsymbol{\mu g} / \mathbf{g m})$ \\
\hline $100 / 25 \mathrm{mg} / \mathrm{kg}$ lopinavir/ritonavir & $18.2 \pm 1.0$ & $0.109 \pm 0.027$ & $0.005 \pm 0.001$ \\
\hline $50 / 12.5 \mathrm{mg} / \mathrm{kg}$ lopinavir/ritonavir & $3.1 \pm 0.3$ & $0.023 \pm 0.002$ & $0.002 \pm 0.001$ \\
\hline
\end{tabular}

